\title{
POE, ENTRE O CINEMA E A LITERATURA: UMA LEITURA INTERMIDIÁTICA DE THE RAVEN
}

Caio Antônio de Medeiros Nóbrega Nunes Gomes*

Universidade Federal da Paraíba João Pessoa, Paraíba, BR

Genilda Azerêdo ${ }^{* *}$

Universidade Federal da Paraíba João Pessoa, Paraíba, BR

\section{Resumo}

Em The Raven (2012), filme dirigido por James McTeigue, além de termos Edgar Allan Poe como protagonista e alusões a vários de seus textos, a relação entre cinema e literatura é ainda mais adensada a partir da presença de questões ligadas à própria materialidade, socialidade e economia da mídia literária. Neste trabalho, fundamentado especialmente nos pressupostos teóricos de Rajewski (2012) e Moser (2006), propomos uma leitura intermidiática de The Raven, em que examinamos o processo de referenciação intermidiática realizada pelo cinema em relação à literatura. Duas conclusões foram alcançadas: i. o filme, ao tornar opaca a mídia literária, procurou esconder sua própria midialidade audiovisual; ii. The Raven se articula com uma série de discursos sobre o escritor estadunidense na contemporaneidade, contribuindo para o fortalecimento da posição de significante cultural de Edgar Allan Poe.

Palavras-chave: Edgar Allan Poe; Cinema e Literatura; Intermidialidade; Referência Intermidiática

\section{POE, BETWEEN CINEMA AND LITERATURE: AN INTERMEDIAL READING OF THE RAVEN}

\begin{abstract}
In The Raven (2012), film directed by James McTeigue, in addition to having Edgar Allan Poe as protagonist and allusions to many of his texts, the relation between cinema and literature is deepened by the presence of issues regarding the medium of literature and its materiality, sociality and economy. This article proposes an intermedial reading of The Raven, aiming to investigate the process of intermedial referencing accomplished by the cinema in relation to literature. Our analysis is supported by theoretical principles drawn especially from Rajewski (2012) and Moser (2006). Finally, two conclusions were established: i. the film, while making the literary medium opaque, concealed its own audiovisual mediality; ii. The Raven associates itself to a series of discourses concerning the contemporary relevance of the American author, contributing to the consolidation of Edgar Allan Poe as a cultural signifier.
\end{abstract}

Keywords: Edgar Allan Poe; Cinema and Literature; Intermediality; Intermedial Reference

\footnotetext{
“Mestrando do Curso de Letras da Universidade Federal da Paraíba. Bolsista do CNPq. E-mail: caioamnobrega@gmail.com

${ }^{* *}$ Doutora em Letras pela Universidade Federal de Santa Catarina. Professora dos cursos de Graduação e Pós-Graduação em Letras da Universidade Federal da Paraíba. Pesquisadora PQ2 do CNPq. E-mail: genildaazeredo@yahoo.com.br
} 
Lançado em 2012, sob a direção de James McTeigue, The Raven (2012) oferece a seus espectadores uma recriação dos últimos dias de vida do escritor estadunidense Edgar Allan Poe. No filme, ambientado em 1849, seguimos uma série de eventos que levam Poe a unir-se aos detetives da cidade de Baltimore, na busca por um assassino em série cujas matanças espelham aquelas das narrativas fantásticas e de mistério do autor. Além de termos Edgar Allan Poe na posição destacada de protagonista, o filme articula-se intertextualmente com vários de seus escritos: inspiram assassinatos, por exemplo, os contos "The murders in the Rue Morgue" e "The Pit and the Pendulum"; o sequestro de Emily (par romântico de Poe no filme) emula aquele descrito em "The Masque of the Red Death"; indícios e interpretações ligados a "The Cask of Amontillado" e "The Tell-Tale Heart" levam, respectivamente, às descobertas de um cadáver nos túneis da cidade e da localização de Emily; são citados ainda os contos "The Mystery of Marie Roget" e "The Facts in the Case of M. Valdemar". Além das narrativas, versos provenientes de alguns poemas de Poe são declamados por ele ou por outros personagens durante o filme, a exemplo de "Annabbel Lee", "A Dream Within a Dream" e, claro, "The Raven", cuja figura do corvo se metaforiza, desde a sequência inicial do longa-metragem, como sendo a do próprio Poe, além de ter servido como inspiração para o título do filme.

Por essa breve introdução, já podemos constatar que The Raven, como produto da mídia cinema, constitui-se significativamente em relação a um dos mais importantes nomes da literatura nos Estados Unidos. Como o título deste artigo já indica, aqui objetivamos desenvolver uma análise que privilegie a relação entre literatura e cinema, especialmente em relação a como a figura de Poe e seu ambiente literário foram acionados e atualizados na narrativa fílmica. Para tanto, elencamos como alicerce teórico as discussões sobre intermidialidade, que se voltam, de maneira geral, às transgressões das fronteiras entre mídias e às contaminações que entre elas ocorrem, quer sejam entre diferentes sistemas semióticos - como em nosso caso, com a relação entre cinema e literatura -, quer sejam entre diferentes partes de um mesmo sistema semiótico (WOLF, 2005, p. 252).
É importante ressaltar que a opção pela intermidialidade para fundamentar nossa argumentação se justifica pelas escolhas criativas que pudemos encontrar no próprio filme. Em The Raven, não somente a vida e a obra de Poe são merecedoras de um olhar crítico mais atento: as próprias circunstâncias (de ordem econômica, técnica, institucional) que permearam o fazer literário do escritor são bastante significativas na narrativa fílmica. A partir da intermidialidade, propomos, então, pensar sobre como The Raven, na condição de produto da mídia cinema, constitui-se substancialmente em relação à mídia literatura e sua paisagem midiática em tempos de Poe; buscaremos, ainda, na esteira da intermidialidade, conjugar a materialidade da mídia literária com os meios social, intelectual e com os dispositivos de difusão de tal época. Cabe-nos, por fim, refletir sobre como as incursões intermidiáticas em um produto de mídia como The Raven podem iluminar questões relativas a uma cultura hollywoodiana e seus "suportes de inscrição, circulação e consumo" (JUSTINO, 2014, p. 21).

Apesar de termos elencado como corpus de análise um filme - produto de mídia - contemporâneo, e do próprio termo intermídia ter sido utilizado pela primeira vez há apenas cinquenta anos, em um artigo de Dick Higgins (DINIZ; VIEIRA, 2012, p. 12), ocorrências intermidiáticas podem ser traçadas desde muito antes dos séculos XX e XXI. A écfrase, por exemplo, entendida como sendo a tradução de uma composição imagética para a linguagem verbal, é alvo de debates que começaram na Grécia Antiga, passando pelo Renascimento e Iluminismo até nossos dias (BARBETTI, 2011, p. 2). Além da écfrase, Rajewski (2012, p. 22) elenca outros fenômenos que podem ser qualificados como intermidiáticos e que, segundo a teórica, já vêm sendo objetos de estudo, há algum tempo, em diversas áreas de conhecimento, como Estudos Literários, História da Arte, Música, Teatro e Estudos de Cinema, entre eles:

transposition d'art, escrita cinematográfica, [...] musicalização da literatura, [...] adaptações cinematográficas de obras literárias, romantizações (transformação de filmes em romances), poesia visual, manuscritos com iluminuras, arte sonora, ópera, quadrinhos, shows multi- 
mídias, hiperficcção (ficção em hipertexto), 'textos' multimídias em computador ou em instalações etc (RAJEWSKI, 2012, p. 22).

A pluralidade e a diversidade de fenômenos intermidiáticos, como podemos constatar acima, fizeram surgir uma definição ampla de intermidialidade como sendo "um termo genérico para todos aqueles fenômenos que (como indica o prefixo inter-) de alguma maneira acontecem entre as mídias" (RAJEWSKI, 2012, p. 18, ênfase no original). Embora não informe significativamente sobre a condição intermidiática de um fenômeno específico - nem sobre a qualidade intermidiática de um determinado produto de mídia -, tal termo genérico é necessário, uma vez que "permite fazer distinções fundamentais entre fenômenos inter, intra e (finalmente) transmidiáticos" (RAJEWSKI, 2012, p. 18). Dessa forma, explica-nos Rajewski (2012, p. 18, ênfase original) que

para cobrir manifestações intermidiáticas específicas e para teorizar uniformemente sobre elas, várias concepções de intermidialidade, concebidas de modo mais restrito (e muitas vezes mutuamente contraditórias), têm sido introduzidas, cada uma com suas próprias premissas explícitas ou implícitas, seus próprios métodos, interesses e terminologias.

Um estudo intermidiático que se volte para a historicidade e o desenvolvimento das mídias poderia propor, por exemplo, que a relação do cinema com a literatura se "dá na própria logística da câmera fotográfica e da sala de projeção, que já são 'literárias', [uma vez] que posicionam a recepção num processo cognitivo que é comum a ambos, literatura e cinema, independente de haver diálogo explícito entre um filme e um romance" (JUSTINO, 2014, p. 27), ou ainda que o cinema pôde surgir a partir de um processo de remediação de mídias anteriores, a saber, a fotografia e o teatro (BOLTER; GRUSIN, 2000). $\mathrm{O}$ fato de podermos nomear nossa abordagem neste artigo (uma busca de como o cinema faz uso da literatura como estratégia poderosa de constituição de sentido) igualmente de intermidiática atesta para a necessidade premente, com a qual os críticos se deparam, de delimitar o escopo e o objetivo de suas investigações.
Com isso em mente, a fim de que possamos articular os cruzamentos entre cinema e literatura em The Raven, elencamos como nosso alicerce teórico as abordagens propostas por Rajewski (2012) e Moser (2006). A primeira delas, apresentada pela teórica alemã Irina Rajewski, caracteriza-se por seu direcionamento sincrônico e pelo entendimento da intermidialidade como categoria para a análise concreta de textos, em detrimento de uma consideração diacrônica das relações intermidiáticas. Sobre tais escolhas, discorre a teórica:
[...] minha abordagem a fenômenos intermi- diáticos segue uma direção sincrônica, pois procura distinguir manifestações diferentes de intermidialidade e desenvolver uma teoria uni- forme para cada uma delas. [...] [F]ocalizo a in- termidialidade [também] como uma categoria para a análise concreta de textos ou de outros tipos de produtos das mídias. [...] [E] u me con- centro nas configurações midiáticas concretas e em suas qualidades intermidiáticas específi- cas (RAJEWSKI, 2012, p. 23).

As opções teóricas empreendidas por Rajewski possibilitaram-na fazer distinções entre grupos de fenômenos intermidiáticos e propor, assim, três subcategorias da intermidialidade. Um olhar sobre cada uma delas, articulando-as com The Raven pode iluminar nossa discussão. Na ordem proposta por Rajewski, temos:

a. Transposição intermidiática: "Intermidialidade no sentido mais restrito de transposição midiática (por exemplo, adaptações cinematográficas e romantizações): aqui a qualidade intermidiática tem a ver com a criação de um produto, isto é, com a transformação de um determinado produto de mídia (um texto, um filme etc.) ou de seu substrato em outra mídia" (RAJEWSKI, 2012, p. 24, ênfase no original).

Em The Raven, podemos perceber entradas intertextuais de vários textos de Poe, como já mencionado. Tais entradas, porém, não passam de um nível superficial, sendo acionadas para compor o enredo maior do próprio filme, especialmente em relação às mortes e à perseguição ao assassino. $\mathrm{O}$ fio condutor que une os 
214 Caio Antônio de Medeiros Nóbrega Nunes Gomes and Genilda Azerêdo, Poe, entre o cinema e a literatura...

textos é o próprio Edgar Allan Poe; o título do filme, afinal, é utilizado para se referir ao escritor estadunidense. O não aproveitamento de tais textos em um nível mais profundo quanto a seu próprio conteúdo não nos permite pensar que o potencial intermidiático em The Raven exista na primeira subcategoria da intermidialidade proposta por Rajewski.

b. Combinação de mídias: "Intermidialidade no sentido mais restrito de combinação de mídias, que abrange fenômenos como ópera, filme, teatro, performance, manuscritos com iluminuras, instalações em computador ou de arte sonora, quadrinhos etc. [...] A qualidade intermidiática dessa categoria é determinada pela constelação midiática que constitui determinado produto de mídia, isto é, o resultado ou o próprio processo de combinar, pelo menos, duas mídias convencionalmente distintas ou, mais exatamente, duas formas midiáticas de articulação" (RAJEWSKI, 2012, p. 24, ênfase no original).

Como um produto da mídia cinema, The Raven já se constitui como um texto intermidiático, uma vez que é composto pelas matrizes imagética, sonora e verbal. Embora possua esse caráter intermidiático, constituindose já como linguagem heterogênea, tendemos a perceber o cinema como gênero único, em uma demonstração de como "a combinação de diferentes formas midiáticas de articulação pode levar à formação de gêneros de arte ou de mídias novos e independentes, em que a estrutura plurimidiática do gênero se torna sua especificidade" (RAJEWSKI, 2012, p. 25).

c. Referências intermidiáticas: "Intermidialidade no sentido mais restrito de referências intermidiáticas, por exemplo, referências, em um texto literário, a um filme, através da evocação ou da imitação de certas técnicas cinematográficas como tomadas em zoom, dissolvências, fades e edição de montagem. [...] As referências intermidiáticas devem, então, ser compreendidas como estratégias de constituição de sentido que contribuem para a significação total do produto: este usa seus próprios meios, seja para se referir a uma obra individual específica produzida em outra mídia [...], seja para se referir a um subsistema midiático específico [...], ou a outra mídia como sistema" (RAJEWSKI, 2012, p. 25, ênfase no original).

Em The Raven, podemos perceber como a narrativa audiovisual se constitui sobremaneira em relação a uma tradição e a um modo de fazer literários. Diferentemente da subcategoria anterior, porém, nas referências intermidiáticas somente uma das mídias está em sua própria materialidade; ou seja, em The Raven, a literatura pode ser apenas evocada, tematizada ou imitada, a partir da linguagem própria do cinema. Quando, por exemplo, assistimos a Edgar Allan Poe segurar em suas mãos seu próprio livro de contos e entramos em contato com a materialidade própria da literatura, conseguimos perceber cinema e literatura (especialmente em sua versão como escrita impressa) como mídias distintas.

Considerando a terceira subcategoria, a das referências intermidiáticas, propomos refletir de que forma The Raven "faz ver e enfatiza o alicerce midiático" (MOSER, 2006, p. 57) da literatura. Por fazê-lo associando a prática literária a seus aspectos materiais, técnicos, econômicos, sociais e institucionais - de fato constituindo a mídia a partir da tríade "sistema-suporte-procedimento em rede" (JUSTINO, 2014, p. 30) -, é a partir da referência intermidiática que salta aos olhos o caráter denso de intermidialidade do filme.

É interessante perceber ainda que, para que possamos captar a midialidade da literatura em The Raven, ou seja, para que a literatura enquanto mídia apareça em sua opacidade (isto é, de modo distanciado), o filme tende a se apresentar enquanto mídia transparente. Moser (2006, p. 56, ênfase no original), fundamentado nas discussões levantadas por Bolter e Grusin em Remediation: understanding new media, ilumina a relação entre mídia e as categorias de opacidade e transparência ao argumentar que

toda mídia nova pretende [...] propiciar acesso direto ao real - ela fará valer então sua transparência, até mesmo sua inexistência (transparency, immediacy) em relação àquilo que vai mediar. Por outro lado, esse apagamento 
da mídia é obtido por um acréscimo no nível do aparelho midiático e a mídia exibirá orgulhosamente sua sofisticação de funcionamento midiático (hypermediacy).

Adaptando uma discussão de Moser (2006) sobre a relação entre cinema e pintura no filme Caravaggio, podemos argumentar que a relação entre transparência e opacidade - neste caso, cinema e literatura - permitiu a McTeigue, a partir das referências à literatura, abrir uma distância entre a condição artística e a prática midiática desenvolvida por Edgar Allan Poe. Os produtos da mídia literatura, ou seja, os textos de Poe tais como inseridos em The Raven, configuram-se como apenas "uma espécie de ponta do iceberg que tem um alicerce invisível, cuja extensão é infinitamente maior que sua ponta" (MOSER, 2006, p. 57). Ao serem enfatizados também os "signos, hábitos, modos de fazer e usar" (JUSTINO, 2014, p. 32) da mídia literatura, aproximamo-nos de uma visão mais completa do iceberg; nesse processo, a midialidade da literatura ganha "concretude e, como consequência, opacidade, podendo assim tornar-se objeto de representação fílmica" (MOSER, 2006, p. 57).

Diversos aspectos da literatura enquanto mídia ${ }^{1}$ (distanciada, re-mediada) são ressaltados no filme, entre eles:

\section{a) Materialiade:}

Escritos de Poe aparecem materializados na narrativa fílmica, a exemplo da sequência em que o Detetive Fields lê uma passagem de um texto enquanto segura um livro escrito pelo autor estadunidense; no final dessa leitura, vemos, em close, com o livro ainda aberto, a página a qual o detetive acabara de ler, para logo em seguida vermos a capa do volume. Em ambas as situações, emergem detalhes de editoração (vemos, no alto da página, que a passagem lida havia sido do conto "The murders in the Rue Morgue"), diagramação, escolhas tipográficas, além da ilustração e detalhes em arabesco da capa do volume. É interessante perceber que essa materialidade pode ser apenas sugerida ou referenciada pela narrativa fílmica. A própria performance de leitura do detetive é determinada pela realidade escrita e impressa do texto de Poe, confirmada pela atenção que recebe logo em seguida quando do enquadramento da câmera. Também merecem destaque as sequências em que nos deparamos com uma folha em branco sendo preenchida pela caligrafia de Poe em tinta negra, enquanto este se encontra no ato de escrita.

\section{b) Economia:}

Aspectos econômicos relacionados à mídia literatura também fazem parte do processo de referenciação intermidiática realizado em The Raven, especialmente em relação às dificuldades econômicas pelas quais passa Poe. Logo no início do filme, vemos Poe entrar em um bar à procura de bebida; após ter seu pedido por uma dose de brandy negado pelo dono do estabelecimento, por falta de pagamento de uma dívida anterior, Poe entra em uma discussão com um desconhecido e, ao afirmar que ele merecia mais respeito por ser um poeta famoso internacionalmente, recebe como resposta que é justamente por ele ser um poeta que ele é tão pobre. A discrepância entre o reconhecimento que Poe adquiriu através de seus escritos e a remuneração por eles recebida também está presente em um diálogo travado com Emily. Ao ser perguntado quanto dinheiro ele conseguiu por seu poema "The Raven", que o próprio Poe clama ser conhecido em todo o mundo, ele admite ter sido pago apenas nove dólares. $\mathrm{O}$ filme, assim, acaba por demonstrar claramente os infortúnios vivenciados pelos críticos, poetas e ficcionistas do início do século XIX, devido à falta de parâmetros da crítica estadunidense e, por consequência, dos editores, que valorizavam a obra pela extensão e por abordar temas e fatos nacionais. Essa falta de parâmetros conduz à desvalorização das obras, sejam elas ficcionais, poéticas ou críticas e, por consequência, expõe os escritores, que não se inseriram no parâmetro estabelecido, à carência econômica. Não por acaso, Fisher (2008, p. 4) argumenta que foi a pobreza o maior demônio de Poe, sua maior fonte de preocupações.

\section{c) Técnica:}

Encontramos aspectos técnicos relacionados à mídia literatura no filme em dois diferentes momentos. $\mathrm{O}$ 
primeiro, que já foi mencionado no ponto sobre a materialidade, diz respeito à técnica utilizada por Poe para manusear os materiais (folha, caneta, tinteiro) a fim de realizar o ato de escrita. $\mathrm{O}$ segundo é relativo à publicação de seus textos em jornal e ao processo de edição, diagramação e impressão que tal tipo de publicação acarreta. Os dois casos compreendem traços técnicos que adensam a referenciação intermidiática realizada pelo filme em relação à mídia literária e ao próprio Poe, escritor que dominava ambas as técnicas de escrita manual e de editoração e publicação impressa (FISHER, 2008, p. 23).

\section{d) Socialidade:}

Quanto ao aspecto social da literatura referenciado no filme, destaca-se a sequência em que Poe lê seu poema "The Raven" em uma reunião para um grupo de senhoras da sociedade de Baltimore. Logo após a leitura, vemos que Poe atua como professor de belas letras, ao ouvir um poema de uma delas e discutir rimas, metáforas e justaposição de sentidos nos versos por ela escritos. A literatura, assim, é alçada a uma posição de prestígio dentro da narrativa fílmica, como atividade digna de ser perseguida por membros das mais altas classes sociais. Ademais, não podemos separar tal aspecto social desenvolvido pelo escritor de sua difícil situação econômica. Convém também ressaltar que Poe, em sua atuação como investigador, acaba por interagir significativamente com o meio social da polícia. Tal inserção (mesmo que irônica, já que os papeis foram invertidos, e o escritor se encontra no papel de leitor/investigador) é bastante interessante e pertinente, iluminando um fato sobre a vida e produção literária de Poe relativamente desconhecido (frente a sua enorme fama como poeta e escritor de contos de horror), já que ele é tido como o pai do gênero policial (THOMS, 2004, p. 133), e, por isso mesmo, o filme acaba recebendo uma substancial injeção de capital simbólico ao trazê-lo como detetive.

\section{e) Institucionalidade:}

Aspectos relativos à institucionalidade da mídia literária são especialmente perceptíveis nas interações de
Poe com o editor do jornal Baltimore Patriot, em que o escritor publicou contos, resenhas e poemas. Em uma determinada sequência, vemos Poe perguntando a seu tipógrafo se o editor fizera novamente alterações em uma de suas resenhas, apenas para descobrir que essa sequer foi publicada. A posição de poder que ocupa o editor fica evidente mais uma vez em um diálogo que ele tem com Poe: ao afirmar que as pessoas gostavam de Longfellow, Poe prontamente responde que isso se deu pelo fato de editores como ele influenciarem o gosto das pessoas. O próprio Poe tinha como "grande ambição fundar e editar sua própria revista, uma solução que lhe teria garantido segurança financeira e controle artístico em meio ao que ele considerava um mercado literário hostil"2 (LJUNGQUIST, 2004, p. 7).

A representação fílmica das práticas e do ambiente literário de Poe, a partir de referências intermidiáticas, vai muito além dos níveis textual e material relativos à literatura; em relação a ambas as mídias implicadas neste processo de referenciação intermidiática, podemos perceber que existe um "alto grau de imbricação entre um regime midiático e o [seu] conjunto de práticas culturais" (MOSER, 2006, p. 59). Já apontamos, há pouco, a relação entre o regime midiático da literatura, seu ambiente e seu conjunto de práticas culturais quando delimitamos diferentes aspectos da literatura que foram alvo de referenciação intermidiática do filme. Resta, assim, a questão referente à mídia própria do filme, sobre como esse, enquanto produto de mídia do cinema, dialoga e se articula com um ambiente e com um conjunto de práticas culturais próprios de sua contemporaneidade.

Comecemos por observar, primeiramente, como a própria materialidade audiovisual foi articulada no filme. Para tanto, retornemos à correspondência entre transparência e opacidade e as mídias cinema e literatura, respectivamente, em The Raven, a partir de um olhar sobre uma sequência específica do filme, a saber, quando Poe escreve o último conto a ser publicado em jornal. A cena se constitui a partir de uma montagem em paralelo, que ora mostra a página em branco sendo preenchida pela caligrafia de Poe, ora mostra os eventos relatados nesta página acontecendo a personagens do próprio filme. Quanto a esta sequência, não podemos 
ter certeza se Emily, tentando escapar de um caixão, corresponde de fato à realidade narrativa do filme ou se é uma ilusão representacional relativa àquilo que foi (d)escrito por Poe. Tal sequência, porém, permite-nos observar, em primeira mão, o cinema tematizando o processo de transposição do verbal para o audiovisual. A forma como a transposição foi possível, a partir de como a gramática e a tecnologia do cinema foram acionadas, mostra-se bastante significativa: nesta sequência, efeitos visuais, advindos de avanços na tecnologia digital, são utilizados como forma de o cinema buscar a transparência de sua mídia (BOLTER, 2005), ao passo que, ao termos enquadrada a folha com a escrita de Poe, o filme nos faz ver a materialidade própria (ou ao menos uma das formas materiais possíveis) da mídia literária, realçando sua opacidade.

O filme, ao buscar sua transparência midiática, permitiu, a partir de referências intermidiáticas à literatura, que tal mídia pudesse ser evidenciada ostensivamente em vários aspectos. Essa forma de representação fílmica, que busca a transparência de sua mídia, tal como podemos perceber em The Raven, articula-se com o que Xavier (2005, p. 41) denominou representação naturalista de Hollywood. De acordo com o teórico, três elementos básicos são responsáveis por tal efeito:

a decupagem clássica apta a produzir o ilusionismo [...][,] a elaboração de um método de interpretação dos atores dentro de princípios naturalistas [...] [e] a escolha por estórias pertencentes a gêneros narrativos bastante estratificados em suas convenções de leitura fácil, e de popularidade comprovada (XAVIER, 2005, p. 41).

Acreditamos que The Raven, em linhas gerais, seja condicionado por tais princípios: apesar do trabalho de referenciação intermidiática que o filme faz em relação à literatura, no que tange a sua própria midialidade audiovisual,

tudo caminha em direção ao controle total da realidade criada pelas imagens - tudo composto, cronometrado e previsto. Ao mesmo tempo, tudo aponta para a invisibilidade dos meios de produção desta realidade. Em todos os níveis, a palavra de ordem é "parecer verdadeiro"; mon- tar um sistema de representação que procura anular a sua presença como trabalho de representação (XAVIER, 2005, p. 41).

Nesse sentido, além da materialidade, também os outros aspectos relativos à mídia literária discutidos anteriormente - economia, técnica, socialidade e institucionalidade - são alcançados a partir de uma transparência da mídia audiovisual.

Convém ressaltar, nesse ponto, que não estamos argumentando aqui que um filme que torne opaca a midialidade cinematográfica seja necessariamente mais interessante ou digno de atenção que um filme que siga uma estética naturalista hollywoodiana. Nossos apontamentos sobre a estética hollywoodiana e The Raven têm o propósito de nos fazer refletir, afinal, sobre o lugar que ocupa Edgar Allan Poe na contemporaneidade, sobre como sua notoriedade foi capaz de mover a indústria cinematográfica a fazer um filme específico que procura recriar os últimos e misteriosos dias de sua vida, um filme, afinal, que acaba sendo substancialmente sobre o próprio escritor, seu ambiente e sua prática literária.

De acordo com Kellner (2004, p. 204-205), o cinema hollywoodiano, como ficou conhecida tal forma de produção fílmica, acabou por se tornar prática hegemônica nos Estados Unidos e dominante em contexto mundial, podendo ser caracterizado por seu modo comercial de produção cinematográfica, altamente industrial e racional, guiado, sobretudo, pela lógica capitalista do lucro. Assim, cabe-nos ainda refletir sobre o alcance e o peso que o nome/personagem Edgar Allan Poe trouxe ao filme, sobre como as possibilidades de lucro que existem em relação a sua vida e obra ultrapassaram a barreira do universo puramente literário. Nas palavras do diretor James McTeigue:

Eu achei o roteiro muito bom - eu devo admitir que não conseguia entender como ele ainda não havia sido produzido, então adotei uma postura bastante proativa no intuito de fazê-lo. Porque encontrar um roteiro, ao menos em Hollywood, que seja capaz de mesclar literatura e apelo ao público de forma bem-sucedida é algo raro, então eu tive que agarrar a oportunidade. ${ }^{3}$ 
A mescla entre o universo literário e a indústria de lucro hollywoodiana fica visível desde o pôster publicitário de The Raven, quando de seu lançamento nas salas de cinema. Na peça publicitária, ${ }^{4}$ temos, a partir do jogo entre as cores preto e vermelho - as quais podemos relacionar ao que tradicionalmente se espera de Poe e de seus escritos de horror e morte -, a criação de uma imagem que iconicamente aponta para o animal corvo; ao trazer o próprio Poe como elemento central, tanto da imagem como um todo, quanto do corvo com asas abertas, podemos ainda inferir sua centralidade dentro da narrativa fílmica. O processo de identificação pelo qual passa um possível espectador ao se deparar com esse pôster é ainda aprofundado quando consideramos os elementos verbais nele presentes - "Do mesmo diretor de $V$ de Vingança" e "John Cusack é Edgar Allan Poe" -, marcada pela estratégia de autorreferenciação realizada por Hollywood, na busca por uma reação afetiva por parte do espectador, por sua empatia e envolvimento emocional. A referência a John Cusack (ator/astro da galáxia hollywoodiana), nesse sentido, é bastante significativa, uma vez que articula a possibilidade de uma "dupla identificação com astro e/ou personagem" (WOLLEN, 2002, p. 75).

De acordo com Kellner (2004, p. 213), a fim de que possamos refletir criticamente sobre Hollywood e os produtos de mídia provenientes de sua indústria cinematográfica, precisamos olhar para seu sistema de produção, seus códigos e fórmulas, e a complexa interação entre filme e sociedade, a saber, sobre como o filme articula discursos de tal sociedade, estando saturado de sentidos provenientes da esfera social. Em nossa discussão sobre The Raven, evidenciamos alguns aspectos relativos à estética hollywoodiana e ponderamos sobre como um filme, produto da mídia cinema, constitui-se em relação a um período e uma prática literária que diferem significativamente da paisagem midiática na qual ele foi composto, no diálogo com diferentes historicidades, séculos XIX e XXI. Um fio condutor mostrou-se importante em nosso percurso intermidiático e intercultural: a figura do próprio Poe.

Nesse sentido, é importante constatar que a centralidade de Poe em The Raven acompanha uma série de discursos, ficcionais ou não, que se articulam em volta da figura do autor, de sua vida e obra, e que transitam na esfera contemporânea. Tal fenômeno é particularmente fácil de ser observado no país natal do escritor, os Estados Unidos, onde há uma abundância de referências a Poe. Segundo Neimeyer (2004, p. 205), Poe aparece em quase todos os lugares, desde

um selo comemorativo emitido pelos Correios dos Estados Unidos a um ligeiramente confuso John Wayne ouvindo Robert Mitchum recitar linhas do poema "Eldorado", escrito por Poe, no faroeste hollywoodiano de mesmo nome. [...] Os Simpsons já fizeram várias alusões a Poe, incluindo uma admirável dramatização em desenho animado de "O Corvo". [...] No universo das mercadorias, a Cerveja Raven criou um pôster publicitário que tem um trocadilho irresistível: "Eu sei que você está no fundo do Poço. Que tal uma Raven?".

A imagem de Poe estampa ainda camisetas, canecas, canetas, marcadores de livro, cartões postais etc. Um time de futebol americano, os Baltimore Ravens, foi nomeado em sua homenagem. Há uma profusão de adaptações de textos escritos por Poe ou de recriações de sua biografia. A título de exemplo, The Raven, filme aqui analisado, é o terceiro longa-metragem que tem tal título (os dois filmes anteriores, de 1935 e 1963, não têm relação com o de 2012).

Tal profusão de alusões a Poe fez com que Neimeyer (2004, p. 206) afirmasse que Edgar Allan Poe já conquistou o status de significante cultural, passando de ícone da cultura popular para representante de uma "meta cultura popular". Segundo o estudioso, a diferença entre cultura popular e a meta cultura popular se dá pelo fato de que a primeira é resultado de uma prática em que pessoas assistiram a uma adaptação fílmica, por exemplo, mas desconhecem o texto literário de Poe que a inspirou, enquanto a segunda pode ser caracterizada por um reconhecimento e associação ao escritor quando pessoas ouvem o nome do time de futebol americano, embora sequer tenham assistido a uma das adaptações fílmicas - e muito menos lido algum de seus textos literários (NEIMEYER, 2004, p. 207).

Nesse sentido, os discursos produzidos sobre Poe acabam por ultrapassar a própria figura do autor, cuja 
experiência real no século XIX tem servido de inspiração para o desenvolvimento de muitas outras narrativas nos séculos XX e XXI. Em The Raven, temos um processo de encontro com o autor, seu tempo e suas práticas literárias, a partir de uma mediação de discursos outros, que não necessariamente dialogam com os textos literários e/ou crítico-teóricos escritos pelo próprio Poe, já que o filme se propõe como uma reinvenção dos últimos dias de vida do autor.

Assim, embora tenhamos um certo distanciamento da própria obra literária de Edgar Allan Poe, no sentido de que em The Raven, por vezes, os textos literários são recuperados a partir de alusões em um nível bastante superficial, há, ainda, uma potência latente no filme, uma vez que esse incita seus espectadores a desenvolverem outras práticas de leitura, seja de escritos do próprio Poe ou de textos provenientes de transposições intermidiáticas para o próprio cinema, ou para os quadrinhos, ópera, etc.

A partir da prática intermidiática que discutimos, tornou-se possível a elaboração de um produto de mídia como The Raven, que se propõe a ser uma narrativa lúdica, policial e de mistério nos moldes do cinema hollywoodiano, ao mesmo tempo em que faz uma reinvenção da própria figura do escritor Edgar Allan Poe.

\section{Notas}

1. Fazemos uso das categorias utilizadas por Moser (2006).

2. Esta e as demais traduções neste artigo são de responsabilidade dos autores.

3. Disponível em: http://www.denofgeek.com/ movies/18817/james-mcteigue-interview-the-ravenpoe-v-for-vendetta-altered-carbon-pg-13-and-more. Acesso em: 28 dez. 2015.

4. O pôster encontra-se disponível em: https:// thecinephiliac.files.wordpress.com/2012/04/theraven-uk-poster.jpg. Acesso em: 19 jan. 2016.

\section{Referências}

BARBETTI, Claire. Ekphrastic medieval visions: a new discussion in interart theory. New York: Palgrave Macmillan, 2011.

BOLTER, Jay David. Transference and transparency: digital technology and the remediation of cinema.
Intermédialités: histoire et théorie des arts, des lettres et des techniques. Montréal, n. 6, 2005, p. 13-26.

BOLTER, Jay David; GRUSIN, Richard. Remediation: understanding new media. Cambridge, MA: MIT Press, 2000.

DINIZ, Thaïs Flores Nogueira; VIEIRA, André Soares. Apresentação. In: (orgs.). Intermidialidade $e$ estudos interartes: desafios da arte contemporânea 2. Belo Horizonte: Rona Editora: FALE/UFMG, 2012, p. 11-14.

FISHER, Benjamin F. The Cambridge introduction to Edgar Allan Poe. Cambridge: Cambridge University Press, 2008.

JUSTINO, Luciano Barbosa. Literatura de multidão $e$ intermidialidade: ensaios sobre ler e escrever o presente. Campina Grande: EDUEPB, 2014.

KELLNER, Douglas. Culture industries. In: MILLER, Toby; STAM, Robert (orgs.). A companion to film theory. Malden: Blackwell, 2004, p. 202-220.

LJUNGQUIST, Kent. The poet as critic. In: HAYES, Kevin J. (org.). The Cambridge companion to Edgar Allan Poe. Cambridge: Cambridge University Press, 2004, p. 7-20.

MOSER, Walter. As relações entre as artes: por uma arqueologia da intermidialidade. ALETRIA: revista de estudos de literatura. Belo Horizonte, v. 14, p. 42-65, 2006.

NEIMEYER, Mark. Poe and popular culture. In: HAYES, Kevin J. (org.). The Cambridge companion to Edgar Allan Poe. Cambridge: Cambridge University Press, 2004, p. 205-224.

RAJEWSKI, Irina O. Intermidialidade, intertextualidade e "remediação": uma perspectiva literária sobre a intermidialidade. In: DINIZ, Thaïs Flores Nogueira (org.). Intermidialidade e estudos interartes: desafios da arte contemporânea. Belo Horizonte: Ed. UFMG, 2012, p. 15-45.

THE RAVEN. Direção: James McTeigue. Produção: Marc D. Evans. Intrepid Pictures, 2012. DVD.

THOMS, Peter. Poe's Dupin and the power of detection. In: HAYES, Kevin J. (org.). The Cambridge companion to Edgar Allan Poe. Cambridge: Cambridge University Press, 2004, p. 133-147.

WOLF, Werner. Intermediality. In: HERMAN, David; JAHN, Manfred; RYAN, Marie-Laure (orgs.). Routledge Encyclopedia of narrative theory. Abingdon e New York: Routledge, 2005, p. 252-256.

WOLLEN, Peter. Godard and counter-cinema. In: FOWLER, Catherine (org.). The European cinema reader. London: Routledge, 2002, p. 74-81. 
XAVIER, Ismail. O discurso cinematográfico: a opacidade e a transparência. 3. ed. São Paulo: Paz e Terra, 2005.

Recebido em: 12/07/2016

Aceito em: 11/10/2016 